\title{
Voices from the Newspaper Club: Patient Life at a State Psychiatric Hospital (1988-1992)
}

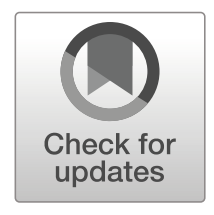

\author{
Emily Beckman ${ }^{1} \cdot$ Elizabeth Nelson $^{1} \cdot$ Modupe Labode $^{2}$
}

Published online: 21 May 2020

(C) This is a U.S. government work and not under copyright protection in the U.S.; foreign copyright protection may apply 2020

\begin{abstract}
The authors conducted a qualitative analysis of thirty-seven issues of The DDU Review, a newsletter produced by residents of the Dual Diagnosis Unit, a residential unit for people who had diagnoses of developmental disability and serious mental illness in the Central State Hospital (Indiana, USA). The analysis of the newsletters produced between September 1988 and June 1992 revealed three major themes: 1) the mundane; 2) good behavior; and 3) advocacy. Contrary to the authors' expectations, the discourse of medicalization - such as relations with physicians, diagnoses, and medications - receive little attention. Instead, the patient-journalists focus on prosaic aspects of institutional life. The patients used their writing as a form self-definition and advocacy. The authors argue that even though it is tempting to consider the patients' emphasis on good behavior as evidence of institutional control, internalized discipline, and medicalization, a more nuanced interpretation, which focuses on how the patients' understood their own experiences, is warranted. Researchers must also recognize the ways in which The DDU Review reveals the patient-journalists' experience of an institutional life that includes nonmedical staff (attendants, secretaries, and therapists), varied social relationships among patients, and negotiated freedoms.
\end{abstract}

Keywords History $\cdot$ Patient narratives $\cdot$ Disability $\cdot$ Mental illness $\cdot$ Intellectual disability · Psychiatric hospitals

The DDU Review was a newsletter published by patients at Indiana's Central State Hospital between 1986-1993. The authors recently discovered forty-two issues of the monthly

Modupe Labode

labodem@si.edu

1 Medical Humanities \& Health Studies, Indiana University-Purdue University Indianapolis, Indianapolis, IN, USA

2 National Museum of American History, Smithsonian Institution, MRC 613, PO Box 37012, Washington, DC 20013-7012, USA 
publication at the Indiana Medical History Museum, located on the former hospital grounds. ${ }^{1}$ Created as part of a recreational therapy program, The DDU Review provides a detailed view of everyday life on the Dual Diagnosis Unit (DDU), a unit that served people with both intellectual disability and serious mental illness. The newsletter evokes the daily routines of a long-stay state psychiatric institution and renders visible the dynamics of the DDU community, prompting us to rethink our understanding of operations of power in mental hospitals and the nature of institutionalized voices.

The DDU Review can be situated within a long history of journalism produced by patients in mental institutions, ranging back to periodicals like The Opal in the nineteenth century (Reiss 2004). Scholars who have examined this history have asked whether patient journalism was an instrument of institutional power or a forum for critique. These analyses have examined asylum journalism in terms of how patients situated themselves in relation to medical superintendents' "top-down," paternalistic authority, and scholars have tended to stake out positions in polar terms: patient writing is either a mouthpiece of the institution, or patients exercise opposition to the hospital through their writing. ${ }^{2}$ However, The DDU Review was produced in collaboration with rehabilitative staff whose goals for the newsletter-fostering patients' independence and advocating for improved conditions at the hospital-harmonized with patients' own interests and desires.

The present work draws on several traditions of scholarship that have aimed to represent and interpret patients' experiences of psychiatric hospitalization. Roy Porter's 1985 call for a medical history "from below" (1985) prompted historians of psychiatry to look to patients' memoirs, letters, journals, and other first-person accounts for what they might reveal about the historical experience of mental illness and its treatment (Bacopoulos-Viau and Fauvel 2016). This tradition of scholarship has been defined by a tension between the desire, following Porter, to recover patients' experiences and agency, and a deep pessimism, following Michel Foucault (1988), about the very possibility of representing the patient's view. Taking up Porter's challenge in recent years, a number of scholars have revealed dialogic interchange between doctors and patients, found hidden patient perspectives by reading case notes "against the grain" (Kelly 2016; Wilson 2010; Murat 2011), recovering the voices and roles not only of patients but also nurses and other actors (Majerus 2016), and demonstrating how the language of the institution can be incorporated by patients and recast into forms of agency (Brian 2011). ${ }^{3}$ Our reading of The DDU Review foregrounds patients' interactions with staff, with the newsletter itself appearing as the product of collaborative interchange. This aspect of our work resonates with care research and disability studies scholarship that have analyzed interdependent relationships between people with disabilities and their caregivers (Kröger 2009).

Scholars, activists, and psychiatric "survivors" associated with the mad studies and mad pride movements have also centered on patients' own accounts of mental illness and institutionalization (Read and Reynolds 1996; Barker, Campbell, and Davidson 1999; LeFrançois, Menzies, and Reaume 2013). While we also privilege patients' own accounts of life inside a psychiatric facility, it is important to note that The DDU Review represents a significant departure from the literature of survivorship and mad pride. Patients in the DDU rarely focused on the lived experience of "madness," defined as "psychic difference, suffering, and unusual states of consciousness" (Lewis 2009). Contrary to what we expected, very few of the articles contain details that would firmly situate them in a psychiatric hospital. Patients did not write about illnesses or diagnoses and only rarely about medications or interactions with doctors. Instead, it is the rather mundane nature of the details that are worthy of consideration. 
This paper analyzes three overlapping themes that emerge in The DDU Review: the mundane; good behavior, and advocacy. The majority of stories in the newsletter were concerned with the minutiae of institutional life, such as meals, relationships, and outings - what we call "the mundane." Why investigate patient narratives that are, at least at first glance, unremarkable? We analyze patient newsletters that discuss, for example, sloppy joes and trips to the zoo, not (simply) because it is exciting to be able to "uncover daily life in all its small, banal details" (Ripa 1990, 42), but because these details were the substance of patients' self-advocacy. Dually diagnosed and doubly-stigmatized, The DDU Review was a site in which patients asserted their fundamental personhood. The newsletters reveal, moreover, how patients sought to improve their lives, not through an individualized process of recovery from illness but rather through practical attention to the material conditions and social relations that shaped their day-to-day lives.

Patients also wrote about plans for securing greater freedoms and, ultimately, release, by practicing consistent "good behavior." Discharge from the hospital, they asserted, would result from staying out of trouble. This emphasis on behavioral control within the newsletter would seem to support a disciplinary reading of its function; we demonstrate, however, that embracing standards of good behavior was intimately tied to patients' own ideals regarding selfsufficiency and independence. Embracing the notion of good behavior, moreover, did not prevent patients and staff from critiquing conditions and policies at the hospital.

After considerable thought, we have decided to use the term "patients" when referring to the authors of the newsletters who were receiving treatment and rehabilitation while living at Central State. The authors of The DDU Review referred to themselves as "patients" and, more rarely, as "residents," within the newsletter itself. Former Central State staff we interviewed between 20172019 primarily use "patients" and "clients" with nurses, physicians, and psychologists tending toward the former and rehabilitation therapists, attendants, and social workers tending toward the latter. In the primary materials from the 1980s and 1990s, rehabilitation specialists and nonmedical staff were more likely to use "patients"; the increase in the use of "clients" reflects shifting attitudes about appropriate terminology among professionals.

Why settle on "patients," then? In the history of psychiatry and in health humanities, the centering of the patient, as opposed to privileging the perspective of physicians, is an important intellectual development. Our work is firmly situated within these traditions. Beyond that, we take a quasi-ethnographic approach with the analysis emerging from the meanings the historical actors themselves assigned to their roles within this arena. DDU Review reporters resided in a hospital that was intended to be, and was often experienced as, a therapeutic community. Further, the contents of the newsletter show that we needn't see this community purely in biomedical terms. This is especially true for patients living within the DDU who had been diagnosed with both a mental illness, for which they were to receive treatment, and intellectual disability, for which they received rehabilitative care.

Within the larger umbrella of experiencing life in a "hospital" in the role of "patient," we see patients engaged in a variety of activities - like the newspaper club - that, though therapeutic, weren't entirely "medical." By the 1970s, psychiatric facilities like CSH had become highly complex, with specialized departments, diverse functions, and an interdisciplinary staff. This can be linked to developments after the First World War when, with the development of therapeutic rehabilitation, hospitals more broadly began to incorporate sports facilities, workshops, and art studios along with biomedical apparatus. ${ }^{4}$ Thus, we assert that the definition of "patients" might expand as "the hospital" continues to change.

Certainly, the term "patients" can be reductive, defining individuals in terms of a supposed medical condition, rather than regarding them holistically as people. When applied to people 
with disabilities, it could imply that disability ought to be understood as a pathological condition that should be treated or cured medically. It is worth emphasizing that our use of the word "patients" is not an attempt to subsume those with dual diagnoses into the medical model. Rather, it is to push from the opposite direction: by placing people with disabilities at the center of an analysis of hospital life, we widen our conception of what "patienthood" entailed. Thus, our use of the term "patients" is not meant to limit or undermine lived experiences but rather to emphasize the fullness of them - to highlight the fact that while people exist (temporarily or indefinitely) in a space of convalescence, they maintain an important sense of individuality, purpose and personhood. We aim, therefore, to analyze the patient experience beyond illness and medicalization and to encapsulate the range of social roles patients played - as reporters, workers, family members, teammates, lovers, and friends-while receiving treatment at $\mathrm{CSH}$.

\section{Background}

Central State Hospital (CSH) opened in 1848 as the "Indiana Hospital for the Insane." Originally located two miles west of Indianapolis, a city that would eventually grow to surround the hospital, CSH was the first and largest of the state's system of psychiatric institutions. Like many state-run mental hospitals in the US, CSH experienced cycles of overcrowding, scandal, and reform (Dwyer 1983). As Indiana and other states began to shift toward community-based care for people with mental illness, the patient population at Central State declined from over twenty-two hundred in the 1950 s to fewer than five hundred in the 1980s. Nonetheless, the 1970s witnessed the creation of specialized units, including the DDU (Dual Diagnosis/Developmental Disabilities Unit), which was certified by the federal government as an "Intermediate Care Facility/Mental Retardation (ICF/MR) in 1978 (Flores n.d.; Centers for Medicare and Medicaid Services, 2020). ${ }^{5}$

As in other hospital units, patients in the DDU interacted with a team of professionals, including psychiatrists, nurses, psychologists, and social workers. As an ICF/MR, moreover, the DDU was dedicated to a program of "active treatment," which ensured that rehabilitation therapists played a large role in patients' day-to-day lives (Central State Hospital 1989). Rehabilitation programs included recreational activities such as sports, ceramics, music appreciation, and camping. The "newspaper club" that produced The DDU Review was founded in 1986 by recreation therapist Bonnie Leftridge, ${ }^{6}$ who was joined by fellow recreation therapist Lisa Freeman and their supervisor, speech pathologist Terry Duwe. Leftridge described the goals of the newspaper program as follows: "It bolsters low self-esteem, develops conversation skills, sharpens academic skills and increases attention span" (Whyde 1988). The DDU Review ran until 1993, and thus documents what would be the final years of Central State Hospital (Duwe, Freeman, and O'Connor 2016; Whyde 1988). In 1992, after investigations into the deaths of several patients shed light on the hospital's significant deficiencies, the governor accepted the recommendation of a special commission to close the hospital by June 30, 1994 (McDonel, Meyer, and Deliberty 1996).

This paper is based on our in-depth narrative analysis of thirty-seven issues of The DDU Review published between September 1988 and June 1992 available in the archives of the Indiana Medical History Museum. Issues of the newsletter were selected based on the holdings of the Indiana Medical History Museum archives though analysis is confined to the extant newsletters created before the announcement of the hospital's closure in June 1992. The newsletters produced 
as the hospital was phased out (after the May-June 1992 issue until the final issue in September 1993) differ significantly enough from earlier articles in tone, content, and production that we have determined that this group of newsletters should be analyzed separately.

In order to understand the patients' experiences of life in the hospital, we relied on a thematic analysis (Morse and Field 1995) that allows themes to emerge from the data rather than to be determined by the researchers (Strauss and Corbin 1998). Each of us independently read and coded each newsletter. After reading and coding approximately every five issues of the newsletter, the investigators met to review codes and identify major themes that required further exploration in subsequent newsletters. This iterative process, in which data are reviewed multiple times and as new themes emerge, is a standard practice in qualitative methodology (Giacomini and Cook 2000). At each meeting, we also determined whether new themes were continuing to emerge with each additional group of newsletters. Analysis continued until no new themes were identified in subsequent editions.

Qualitative research involves several steps to ensure "credibility," a term that is conceptually similar to "validity" in quantitative studies (Giacomini and Cook 2000). In this study, we took the following steps to ensure credibility: independent coding of all data by more than one investigator; analysis from three disciplinary perspectives (a medical humanist, Emily Beckman; a medical historian and public historian, Elizabeth Nelson; and a public historian and museum studies scholar, Modupe Labode) and a process of analysis that continued until saturation of a theme was reached. Results were presented to a group of scholars for feedback and recommendations.

From the set of thirty-seven newsletters we analyzed, we identified three distinct, though often overlapping, themes regarding patients' reported experiences living at CSH: the mundane; good behavior; and advocacy. ${ }^{7}$

\section{The mundane}

In their articles, patients wrote mainly about events in their everyday lives. More rarely, $D D U$ Review reporters conducted interviews (mainly with hospital staff or fellow patients), or reported on current events of local and national interest, such as the Mike Tyson rape trial and the death of Ryan White (Higgins 2015; Shipp 1992). ${ }^{8}$ Common topics that appear in many newspaper stories include food served at the hospital, special events and outings, and relationships with other patients or hospital staff. The article, "My Communication Class," by Linda S. is representative (Fig. 1). In its entirety it reads:

My teacher is George Welch. He has me for class on Tuesdays and Thursdays. I'm working on Survival words and Basic Concepts. I know a whole bunch of basic survival words. I have George Welch for my ward group too.

Sometimes we color, play games, talk, look at pictures and go to the library. For a special treat, our ward group went to Dairy Queen on the bus off grounds. George drove us. We got milkshakes because we didn't have enough money for sandwiches. I loved it. George said if we do a good job in class maybe we can go again sometime (Linda S. 1988b).

Many articles were conversational and included terms that came from life in the DDU, such as "survival words" and "ward group," as well as places important to patients, such as the library and trips outside the hospital. 


\section{MY OOMMNICATION CIASS}

\section{By Linda}

My teacher is George Welch. He has me for class on Tuesdays and Thursdays. I'm working on Survival words and Basic Concepts. I know a whole bunch of basic survival words. I have George Welch for my ward group too. Sometimes we color, play games, talk, look at pictures and go to the library. For a special treat, our ward group went to Dairy queen on the bus off grounds. George drove us. We got milkshakes because we didn't have enough money for sandwiches. I loved it. George said if we do a good job in class maybe we can go again sometime.

Fig. 1 Linda S. carefully describes the details of her day and her relationship to a staff member in this article that appeared in a 1988 issue of The DDU Review

Food, one of the most commonly reported topics, is an important aspect of institutional life in schools, prisons, nursing homes, and hospitals, so its centrality in The DDU Review is not surprising (Godderis 2006). At Central State, mealtimes represented a nexus of caring practices: nutritionists and nurses attended to the effects of particular foods on patients' bodily health, and DDU rehabilitative staff used mealtimes to practice social skills, safety habits, and self-sufficiency. In their articles, patients in the DDU described food primarily in terms of pleasure and community. They described how they felt about the quality and quantity of food served in the hospital's cafeterias.

Celebrations at the hospital, including parties marking retirements, birthdays, and holidays, usually involved special food. These events were modest, but cake, soft drinks, hot dogs, and potato chips made for pleasurable breaks from routine. The staff occasionally prepared meals for the patients at cookouts or provided "homecooked" meals on the ward. These events may have mimicked idealized family gatherings. The articles about parties and other special events often concluded with somewhat formal expressions of gratitude to the staff-including therapists and attendants - who organized the celebrations or cooked the meals.

On Saturday, August 4th Ward 35 individuals were treated to a homestyle breakfast There was homestyle biscuits, scrambled eggs, and sausage. There was jams, jelly and even homemade apple butter.

The part of the homestyle breakfast I liked was homestyle biscuits. Thanks Ms. Miller, Ms. Hampton, and Dan for the delicious homestyle breakfast. PS: we also had fried tomatoes (Tracey E. 1990b).

Patients had special appreciation for staff members who went "above and beyond" to create a festive atmosphere and provide tasty meals. 
Patients often described staff members with whom they were on good terms as "friends" or "best friends":

She gives me colorbooks and crayons. I like to look at her pictures of her kids on her desk. Her kids are Marcus and Kenisha.

Pat is nice to me sometimes. She lets me visit and sit in her office and talk to her. She is pretty with curly hair. She is my best friend (Linda S. 1988).

When authors wrote complementary articles about staff members-including therapists, secretaries, attendants, and janitors - they sometimes alluded to how other, less praiseworthy staff treated residents.

June 15th the Evans Building professional staff held a barbeque pitch-in dinner for all the attendants from here... Me and all the patients appreciate all the attendants that work with us on Ward 35. We appreciate the ones who are detailed and work overtime on our ward. We like our attendants too because they take care of us and treat us like people (Charles J. and John L. 1989).

Patients wrote extensively about their ability to move around the hospital on their own. Many of the patients in the DDU had "grounds privileges" or permission to walk throughout the hospital's sprawling campus. They navigated among buildings as they went to the cafeteria, took classes, exercised in the gym, went to jobs, picked up their checks at the payroll office, and relaxed on the basketball court or at the hospital's café, the Brass Rail.

I take walks to the Library, then I go to the Brass Rail. I take a walk by the Administration building. I look around and watch the airplanes. I like to get out for a little while.

I take walks to stay out of trouble. . . .I think it is fun to take walks (Tim G. 1991).

Patients also ventured off grounds, as staff at the DDU believed that visits to zoos, parks, Special Olympics tournaments, and even shopping or going on drives around town, were important components of therapy and preparing residents for future life in group homes or other places "in the community," that is, outside the hospital grounds:

We went on a hayride at Eagle Creek. D.C. took a lot of us on the bus. It was fun. After the hay ride, we roasted hot dogs and s'mores. We told scary stories and listened to the radio.

The ball game was on the radio. Everyone said "Let's listen to the game on the radio." This is what happened on Oct. 20, 1988 at 6:30. Where: Eagle Creek. We saw three deer (Sam C. 1988a).

Some temporary departures, such as outings with relatives or spending days away from the hospital on a home visit, appeared to have special significance, perhaps because they were an opportunity to connect with family members and were milestones in a patient's exercise of self-control. Patients could have their grounds privileges extended if they demonstrated their ability to control their temper and impulses and demonstrate "good behavior," discussed below. Conversely, staff could limit or revoke a patient's privileges, if their behavior was impetuous or dangerous, or if they broke rules, such as by running away. 


\section{"Good behavior"}

"Good behavior" was another pervasive theme that appears in The DDU Review, one that overlaps significantly with many of the others. Access to good food, increased freedoms, including the ability to leave the hospital for outings or family visits: these were all seen as rewards for good behavior. Indeed, there was a program of awarding points for good behavior on the DDU, associated with monetary rewards (pink slips) and the opportunity to spend time off grounds visiting family. Jeffrey S. concisely described this system:

Steps go by 1, 2, 3, 4 .

When you go to all your activities, you get on step 4. I did and I got more money. I didn't go to all my activities one day and I got back on step 3. I get more money on step 4. And I get to go home more days on step 4. On step 3, I get $\$ 2.50$ four days a week (Jeffrey S. 1988).

As a rehabilitative tool, The DDU Review aimed to encourage appropriate behaviors and build both academic and social skills. Therapists used sections of The DDU Review to impress these goals on residents and to provide incentives for adopting them. See, for example, this article from speech pathologist Terry Duwe's regular "Speak Easy" column (Fig. 2):

The Speech Dept. is picking several patients with improved attitudes, communication skills and attendance in speech and hearing programs. They will be rewarded with a special activity — lunch at a restaurant and a walking tour.

Speech hopes to reward their hard work and provide a carryover situation in the community. We hope to see socialization among peers, polite and mannerly requests and carryover of basic sight vocabulary skills (Duwe 1988).

What comes through here is the complexity of rehabilitation program design, which targets attitudes, skills, and behaviors. As described by Duwe, a system of rewards encouraged patients to work toward a range of interconnected goals with the rewards themselves (such as lunch and a walking tour) acting as additional reinforcement, opportunities for patients to apply what they have learned - essentially, rehearsing living in the community in anticipation of possible release.

Therapists worked with patients on academic knowledge, personal safety and interpersonal skills, all of which were reflected and reinforced in DDU Review articles. For example, patients offered words of advice for safety when eating, "People eat slow. Take small bites. Cut up your food, so you won't get choked. It's real scary when you almost die" (Tommy M. 1988). They also focused on personal growth and conventional etiquette, "To be cool you should take a bath and wash up everyday with soap and water. You should wash your hair everyday and grease it . . . To be cool, ladies should be clean and don't pee in the bed" (Charles J. 1989a). Charles' recommendations move beyond simple instruction on etiquette and hygiene, extending to advice which might improve interpersonal relationships and "coolness." Patients also offered advice regarding the practice of "safe sex," which worked to enforce norms and protect health, while also promoting personal dignity, "Patients at the hospital should have safe sex. When a man and a woman want to have safe sex they should do so in a private place. You can get condoms from staff" (Tracey E. 1990a). Patients used the newsletters to share the useful information they learned in various rehabilitative activities and programs. 


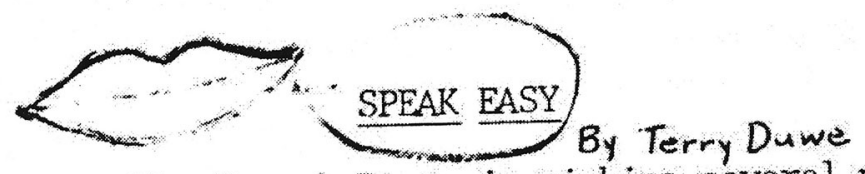

The Speech Dept. is picking several patients with improved attitudes, commication skills and attendance in speech and hearing programs. They will be rewarded with a special activity - lunch at a restaurant and a walking tour. Speech hopes to reward their hard work
and provide a carryover situation in the
commity. We hope to see socialization
among peers, polite and mannerly requests
and carryover of basic sight vocabulary
skills.

Fig. 2 In September 1988 issue of The DDU Review, speech pathologist Terry Duwe used the newsletter to publicly recognize the achievements and behavior of program participants. Artists among the residents of the DDU provided many of the line drawings in the newsletter's early years (Duwe, Freeman, and O'Connor 2016)

Poor behavior or a "bad attitude" could result in penalties, and patients asserted that such behavior would set back a resident's progress toward release. The articles often outlined what actions constituted poor behavior, such as "fighting, stealing, arguing, fussing and patients. . . bossing other patients" (Sam C. 1988b). Some patients wrote about when they had engaged in "bad" behavior, such as fighting with staff or striking another patient: "I wasn't good last night. I was acting real bad" (Linda S. 1989). Residents also described their successful attempts to control their responses to provocations.

In this way, the newsletters helped patients to enact what Michel Foucault (1988) would have called "technologies of the self," a process whereby patients, as disciplinary subjects, internalized behavioral norms. Newsletters provided patients with a forum to publicly take stock of their "bad behavior" and commit to behavioral change: "The first thing I'm going to do is make sure I take my medicine and my shower when it is due. I want to do good and I want people to know me for what I can do instead of what I used to be" (Kenneth S. 1989).

At times, writers denounced the behavior of other patients:

I was disappointed in all of us patients for blowing rollerskating. Some people were horseplaying. Donita told Bonnie that everyone was being bad and acting up. I went to my room. I laid down and went to sleep. I was mad at the patients. 
I was mad because I really wanted to go rollerskating. I like rollerskating. I hope we get to skate when we re-schedule it. Everybody quit acting like little boys and girls. Get yourself together so we can go rollerskating (Jimmy J. 1990).

In this way, patients surveilled one another's behavior and placed these behaviors in full panoptical view through publication. In turn, praising and condemning the behavior of others crystallized reporters' own internal sense of what behaviors were appropriate.

It is tempting to regard such participation - the taking on of the gaze of institutional authority - as an example of the hegemonic nature of the "total" institution in which norms and directives were absorbed by disciplinary subjects. However, from another point of view, one might assert instead that the community as a whole (including both patients and therapists) adopted and promoted shared norms and goals through technologies like The DDU Review. After all, the ultimate goal for many patients - to be discharged from the hospital and pursue a more independent lifestyle - was also the goal of rehabilitation therapists who sought, above all, to prepare patients for life in the community.

\section{Advocacy}

Patients' and therapists' shared goal of achieving greater independence points to new ways to explore patients' writing. Gibson, Carnevale and King (2012) propose the "assemblage" as an "alternative lens for conceptualizing relationships between disabled people, their technologies and caregivers." They do so through a close analysis of the life of a twelve-year-old girl who, due to her rare neuromuscular disorder, requires round-the-clock assistance for the activities of daily living. This assistance is provided by a range of people and technologies, including a wheelchair, a ventilator, a nurse, and her parents. Following Deleuze and Guattari, the authors describe various combinations of the girl, the people, and technologies as "assemblages," each able to "achieve ... a set of effects." It is through engagement and interdependency that the assemblage achieves certain outcomes. The authors conclude that, instead of thinking of helping people with disabilities to achieve independence as the goal of rehabilitation therapy, therapists might do better to think of their task as one of making creative assemblages.

$\mathrm{CSH}$ therapists needed to be creative when establishing a newspaper program, as many patients in the DDU lacked the ability to read or write. Nevertheless, because the DDU was an accredited unit, it had significantly more resources (including a much lower ratio of patients to staff and a supportive administrator) than other units in the hospital. Thus, the hospital could afford the staff time for the intensive one-on-one work necessary for the creation of The DDU Review.

The ideal of independence pervades The DDU Review, even though the paper itself was created through interdependent, collaborative interactions. Some patients did work relatively independently on their articles and were praised for doing so. A staff member wrote in a November 1988 profile piece, "Sam has been a reporter at the DDU Review for $1 \frac{1}{2}$ years. He initiates ideas, writes articles independently, and especially enjoys conducting interviews. We are proud to have him as a reporter!" (DDU Review 1988). However, therapists provided assistance to most of the reporters, helping them to come up with story ideas and generate copy with prompts such as, "How was your visit home?" Patients would then respond orally, dictating their articles to Leftridge, who typed them. Leftridge described the process as follows: 
When I first came up with idea, Terry was my supervisor and she said, "They can't write a newspaper! They can't even hardly put three sentences together."

And I said, "Well, you know they can talk to us, and we can write down what they say." So we might go up to a resident, Linda for example, and say "Linda, how was your weekend?" and she might say, "It was good." So the article might be called:

Linda's Weekend

I had a good weekend.

[Therapist:] "What did you do, Linda?"

I went home to visit my mom.

So we would just write down the words that they said, and it became theirs. And so when the newspaper came out, and they saw their name, they're like: 'I'm a reporter! I wrote an article!" And it really made them feel proud of themselves (Duwe, Freeman, O’Connor 2016).

Stories were therefore produced through dialogic interchange between patients and their therapists. In the published version however, the therapists' contributions to the dialogue were omitted. Implicit in this omission is the notion that the therapists' role was to merely transcribe, in a purely instrumental fashion, the authentic voices of the patients in a way comparable to speech-to-text technologies currently used in educational and rehabilitative settings to assist people with disabilities in the act of writing. Indeed, because the therapist-led processes of interrogation and dictation allowed patients to author articles they could not have written independently, we might view the therapists themselves as assistive technologies that expanded patients' functional capacities. Together with the typewriter or computer, the therapists formed part of an assemblage, one that sustained the publication of The DDU Review for seven years.

To understand The DDU Review in this light is not to diminish the accomplishments of the patients who contributed to it but rather to acknowledge the often-overlooked role of recreation therapists who were also contributors. Their roles as mediators of patients' voices was a substantive one. They played a significant role in prompting story ideas and shaping the direction that stories could take, and thus it is fair to regard the narratives that appeared in The DDU Review as co-constructed though in a manner that is best described as collaborative rather than coercive. After all, the therapists' orientation, while "disciplinary," was ultimately aimed at maximizing the independence and quality of life for patients within the DDU.

The $D D U$ Review allowed patients and therapists to publicize their shared concerns about subpar conditions in the hospital. "The Dirty Nasty Gym and Bathrooms" (Fig. 3) is one of many articles in which patient-reporters exposed conditions they faced, such as uncleanliness, poor food choices, low pay for hourly work, exposure to violence, and lack of freedom:

On Monday, February 3rd we had Slim Gym with Bonnie Leftridge down in the gym. We all said that it was nasty and dirty with trash all over the floor and under the bleachers and around the desk... Someone needs to clean the gym, the office and the three bathrooms and the halls. It needs to be cleaned spotless. No one likes a nasty, dirty gym. Someone please clean the gym every day! (Barbara H. 1992)

The DDU Review provided a space for patients to voice grievances. As the newsletter was distributed to hospital administrators, state officials, patients' families, and advocates, patientreporters brought needed attention to the living conditions in the hospital. During the summer 


\section{THE DIRTY, NASTY GYM AND BATHROOMS \\ By Barbara}

On Monday, February 3 rd we had slim
Gym with Bonnie Leftridge down in the gym.
We all said that it was nasty and dirty
with trash all over the floor and under
the bleachers and around the desk. Ralph
volunteered to sweep the insulation and
some trash around the wall. The floors
were dirty and filthy. The gym office was
also dirty. Someone needs to clean the
gym, the office and the three bathrooms
and the halls. It needs to be cleaned
spotless. No one likes a nasty, dirty gym.
someone please clean the gym every day!

Fig. 3 In her indignant description of the filthy gymnasium, Barbara H. revealed that hospital residents did not passively accept the neglected conditions of the facilities and used The DDU Review as a vehicle for protest

of 1989, for example, inadequate air conditioning in the DDU wards sparked a number of articles, such as "It's Too Hot in This Building," which included the complaint, "It's too sweaty in here, and I have to take my shirt off. Fix the air conditioner!" (Charles J. 1989c).

Access to desirable food and drink and complaints about unequal treatment were also voiced. Barbara H. noted that while staff had access to "good cold water" stored in a separate container, the "clients doesn't get to drink the good water. We have to drink that awful bad water out of the water fountain" (Barbara H. 1989). Charles J. reacted to the replacement of a soda machine:

They took my Mountain Dew out! They took the old pop machines out and put new ones in, and the new ones have Pepsi, Orange, Diet, but not MOUNTAIN DEW!!! I'll go crazy without it... Please, please put my Mountain Dew back!!! P L E A S E!!!

(Charles J. 1989b)

At the basis of these complaints were the assertions that the patients deserved clean and comfortable facilities, adequate food and water, and the opportunity to make choices. Although the deplorable conditions of many psychiatric hospitals are often a given, these articles provide the rare opportunity to take note that the patients believed that they deserved better than what they received.

Therapists encouraged patients to write about these issues. As Freeman later recalled, The $D D U$ Review "brought light to some problems that Central State had: clogged toilets in the 
gym, buses that broke down all the time, faulty air conditioning systems. And patients could write about that and what was going on in the building. We made sure that that the governor got a copy of The DDU Review every month, as did all the state legislators, in addition to family members. So we were a little bit ornery in that regard" (Duwe, Freeman, O'Connor 2016). In a few instances, therapists themselves penned articles that alerted readers to the hospital's inadequate resources. For example, in a 1988 article, Leftridge reported: "The Rehab staff is sad to announce that due to the poor condition of our facility buses, we may not be taking as many off-grounds trips as before. We are really sorry for this inconvenience, but we do not want to risk your lives by driving buses that are always breaking down. We care about you too much!!!” (Leftridge 1988)

The critical stance of the newsletter took on additional significance as a string of preventable patient deaths brought state authorities to investigate and eventually close the hospital. Vincent N. wrote:

I want a law-No Smoking after 8 p.m. Sunday through Thursday... Smoking in the restrooms is a fire hazard. It is a matter of life and death for everybody who stays in this building... Too many residents are bugging the ward staff to go out to smoke. The ones with full grounds are the problem. ${ }^{9}$ Since we had that one fire for real we're trying to save each others [sic] lives (Vincent N. 1989).

Just weeks after Vincent N.'s article was printed, another patient, Cynthia Stanley, accidentally set herself on fire while smoking in a hospital restroom. As Jason H. reported, "At 8:30 P. M. Thursday night, on 11/2/89 Cynthia Stanley died. The reasons why Cynthia died was she was burnt pretty bad on 80 percent of her body" (Jason H. 1989).

While the hospital was scrutinized by journalists and officials, DDU reporters also conducted their own investigations. After a patient's death by overmedication, The DDU Review conducted a survey among the residents: "Do you take too much medicine?" Ten out of twenty-three respondents answered "yes" (DDU Review 1992). DDU Review reporter Jason H. even interviewed Governor Evan Bayh in the summer of 1992. Bayh said, "I think it is important to provide the best environment for you, the other residents and the staff who work here." That same month, Bayh announced that the hospital would close within the next two years, by June 30, 1994 (Dwyer 2019).

\section{Conclusion}

In understanding the human response to illness, Howard Brody has highlighted the importance of stories, "stories about what the sickness means to the individual and how the individual perceives the events that are occurring" (2003, 3). Brody's insight encourages us to listen closely to how patients narrated their own lives. As we read The DDU Review, we find ourselves confronted by the unexpected: a palpable sense of agency among the patients, robust social bonds, pleasures, and even freedoms. This is not to downplay those stories that recount filthy living conditions, violent conflicts, and patient deaths resulting from neglect. However, it is to underscore what we had not foreseen: the routine life of a community within the hospital. This was a community that encouraged education, self-expression, and personal growth - even as, it turns out, the hospital was on the verge of collapse.

While "illness" and "disability" defined the community in which the patient-reporters found themselves, it did not necessarily define how they lived day to day, nor how they presented 
their lives to their readers. Traditional paradigms for understanding the history of mental institutions have emphasized the medicalization of insanity and the disciplinary functions of the psychiatric hospital. Such accounts posit an oppositional relationship between patients and staff and view patient writings in terms of the authentic expression of the lived experience of madness, as protests against institutional power or as examples of the hegemony of psychiatric discourse. We have found these frameworks to be largely inadequate for understanding The DDU Review. Patients focused on practical matters, such as negotiating the social world of the hospital and the possibility of accessing better resources and greater freedoms, rather than on their subjective experiences of mental illness and healing. Doctors and nurses are largely absent from their stories as are discussions of diagnoses or doctor-prescribed therapies (such as medications). On the other hand, recreational therapists, speech therapists, social workers, attendants, janitors, and other non-medical staff are key players in patients' articles. It is clear that many of these staff members became patient advocates, encouraging patients to expand their capacity for independent living from a perspective of developing creative assemblages. The newsletter also allowed patients and therapists to protest together against poor conditions in the hospital. Subsequently, patients were encouraged and became advocates for one another and for themselves.

Finally, for patients in the DDU, the acceptance of disciplinary norms was experienced as a form of self-empowerment. Certainly, The DDU Review was a disciplinary technology, one that encouraged patients to internalize the directives of hospital authorities. Many authors wrote as if there was a direct line from good behavior to discharge from CSH. At the same time, we might see good behavior-based in principles such as social etiquette, personal safety, non-violence, hygiene, and sexual consent - as more than the imposition of institutional control. For an incarcerated and stigmatized population, such knowledge (whether strategically adopted or not) may have felt empowering, opening up a wider range of opportunities for self-determination. Indeed, most DDU Review reporters assumed that their choices could define their quality of life within the hospital and that they could work toward securing their release from the facility and live more independently. The system of rewards and punishments put into place by hospital authorities gave patients clear instructions for gaining wider spheres of freedom through the exhibition of "good behavior."

If we consider the stigma that surrounded (and continues to surround) both disability and mental illness, the palpable optimism expressed in the newsletter might be read as tragic. When we widen the frame to include what patients could not have known - that more patient deaths would soon follow, that the hospital would be ordered to close, that most patients would be dispersed to other institutions offering round-the-clock surveillance such as state hospitals, nursing homes, and group homes - one might conclude that patients' sense of control over their own destinies was misguided. From a historical perspective, capturing patients' attitudes and expectations before the hospital closure provides valuable data for assessing the impact of deinstitutionalization (or re-institutionalization) on individuals' quality of life. For example, analyzing the interdependent relationships that developed between caregivers and patients adds nuance to our understanding of what was possible at a late-twentieth-century psychiatric institution.

From a clinical perspective, moreover, the exploration of patient voices through these newsletters provides a means for better understanding what patients might want, need and expect, which can ultimately help when determining treatment and making decisions. Providing space for patients with disabilities, as well as those who are chronically ill and/or 
hospitalized long term, to simply strive for what is ordinary may be the key to optimal care, beyond expressly medical interventions. Providing social and technological support to bridge striving and reality is even better.

In addition to its clinical and historical implications, The DDU Review connects with us as human beings. Access to these patients' voices inevitably stretches our moral imaginations so that we are better able to consider what it is like to be someone else. We not only develop empathy and extend it to others, but we more fully identify with other human beings' responses to illness and hospitalization. Further research is needed to determine whether The DDU Review should be read primarily in terms of its exceptional qualities - as a detailed evocation of the lives of a small subset of patients, in the charge of particularly dedicated therapists, on one ward in a specific hospital — or whether the newsletter sheds light on a more general experience of institutional life in the period. Either way, we uphold the value of listening to patient voices wherever they can be found, without allowing preconceived notions to diminish what they have to say.

Acknowledgements The authors would like to thank the journal editors and the anonymous reviewer for their astute and helpful critique.

Compliance with Ethical Standards No funding was received to conduct the research in this article

Conflict of Interest Dr. Emily Beckman declares that she has no conflict of interest.

Dr. Elizabeth Nelson declares that she has no conflict of interest.

Dr. Modupe Labode declares that she has no conflict of interest.

Ethical Approval This article does not contain any studies with animals performed by any of the authors.

Statement on Human Rights This article is based on publicly available archival materials and as such, falls outside of the purview of the authors' Institutional Review Board. The authors have not been able to trace the patients who wrote articles for The DDU Review. To preserve the anonymity of writers while also acknowledging the importance of each individual's production, the authors have referred to the individual authors by their first name and the initial of their surname (for example, Linda S.).

\section{Endnotes}

1 The Indiana Medical History Museum's collection of Central State Hospital newsletters also includes The Central Observer (1970-1971) and The Local Bahr (1991-1993). The DDU Review holdings include forty-two issues published from September 1988 until September 1993. The earliest issues (dating from October 1986August 1988, along with January 1991-June 1991 and July-August 1992) have not been located.

2 As Reiss (2004, 23, f.n. 5) notes: "Erving Goffman wrote that 'house organs'-newsletters written by patients - are little more than vehicles for patients to voice 'the institutional line' on issues affecting their lives (96). Jann Matlock, writing about a nineteenth-century woman's surreptitious asylum journal, arrives at an equally sweeping but precisely opposite conclusion: 'Writing in the asylum is always transgression. It is always an attempt to get beyond the asylum, to make sense out of being locked up, to reclaim an identity other than the one conferred by the system, to procure an inviolable space' (168-69)." Reiss is referencing Erving Goffman (1961) Asylums: Essays on the Social Situation of Mental Patients and Other Inmates (New York: Doubleday) and Jann Matlock (1991) "Doubling Out of the Crazy House: Gender, Autobiography, and the Insane Asylum System in Nineteenth-Century France," Representations 34 (1991):166-195.

${ }^{3}$ See, for example, Kathleen Brian's elegant examination of the appropriation of medical discourse - in this case, the nascent language of eugenics - in Anna Agnew's institutional memoir From Under the Cloud, or Personal Reminscences of Insanity (1886), a text also created by a patient at Central State, then called the Indiana Hospital for the Insane.

${ }^{4}$ Indeed, psychiatric hospitals in particular have incorporated rehabilitative techniques that exceed the purely biomedical since the advent of the "moral treatment" in the mid-nineteenth century.

${ }^{5}$ As of 2010, these facilities are called Intermediate Care Facilities for Individuals with Intellectual Disabilities (ICF/IID). 
${ }^{6}$ Today, Bonnie Leftridge is known as Bonnie O'Connor.

7 The authors have not been able to trace the patients who wrote articles for The DDU Review. To preserve the anonymity of writers while also acknowledging the importance of each individual's production, the authors have referred to the individual authors by their first name and the initial of their surname (for example, Linda S.).

${ }^{8}$ Ryan White (1971-1990) used his experience of living with HIV/AIDS to fight discrimination and stigma against people with HIV/AIDS. Many celebrities who supported his activism attended his funeral in Indianapolis. In 1992, heavyweight boxing champion Mike Tyson was convicted of raping an eighteen-year-old woman. The trial was held in Indianapolis, where the crime occurred in July 1991. The national media extensively covered both events.

${ }^{9}$ Having "full grounds" was the hospital's term for a level of privilege in which the resident was permitted having the privilege to move freely throughout the entire hospital grounds on their own.

\section{References}

Bacopoulos-Viau, A. and A. Fauvel. 2016. “The Patient's Turn: Roy Porter and Psychiatry’s Tales, Thirty Years On." Medical History 60 (1):1-18.

Barker, P., P. Campbell, and B. Davidson, eds. 1999. From the Ashes of Experience: Reflections on Madness, Survival and Growth. London: Whurr Publishers.

Brian, K.M. 2011. "The Reclamation of Anna Agnew: Violence, Victimhood, and the Uses of 'Cure." Journal of Literary and Cultural Disability Studies 5 (3): 279-302.

Brody, H. 2003. Stories of Sickness. Oxford and New York: Oxford University Press.

Centers for Medicare and Medicaid Services. "Intermediate Care Facilities for Individuals with Intellectual Disabilities.” 2020. https://www.cms.gov/Regulations-and-Guidance/Legislation/CFCsAndCoPs/IntermediateCare-Facilities-for-Individuals-with-Intellectual-Disabilities-ICF-IID. Accessed 13 May 2020.

Central State Hospital.1989. 142nd Annual Report. Indianapolis: State of Indiana.

C., Sam. 1988a. "The Hay Ride." The DDU Review. October. - 1988b. "Ward 34 News." The DDU Review. September.

DDU Review. 1988. "Reporter of the Month: Up Close and Personal." November.

DDU Review. 1992. "Special Feature.” March-April.

Duwe, Terry. 1988. "Speak Easy." The DDU Review. September.

Duwe, Terry, Lisa Freeman, and Bonnie O’Connor. 2016. Personal communications. August and November.

Dwyer, E. 1983. "Mental Health Care in Early Twentieth Century Indiana and the Limits of Reform." Indiana Medical History Quarterly 9:23-27.

—. 2019. "The Final Years of Central State Hospital." Journal of the History of Medicine and Allied Sciences 74 (1): 107-126.

E., Tracy. 1990a. "Safe Sex." The DDU Review, June.

1990b. "Ward 35 Gets a Homestyle Breakfast." The DDU Review. August.

Flores, Mike. n.d. "Employment Narrative: Central State Hospital." Personal Files. In the authors' possession.

Foucault, M. 1988. Technologies of the Self: A Seminar with Michel Foucault. Edited by L. H. Martin, H. Gutman, and P. H. Hutton. Amherst: University of Massachusetts Press.

G., Tim. 1991. "Taking Walks." The DDU Review. July.

Giacomini M.K. and D. J. Cook. 2000. "Users' Guides to the Medical Literature: XXIII. Qualitative Research in Health Care A. Are the Results of the Study Valid? Evidence-Based Medicine Working Group." Journal of the American Medical Association 284:357-362.

Gibson, B. E, F. A. Carnevale, and G. King. 2012 “"This is my way’: Reimagining Disability, In/dependence and Interconnectedness of Persons and Assistive Technologies.” Disability and Rehabilitation 34 (22): 18941899.

Godderis, B. 2006. "Food for Thought: An Analysis of Power and Identity in Prison Food Narratives." Berkeley Journal of Sociology 50:61-75.

H., Barbara. 1989. "APS Workshop Gets a Water Container.” The DDU Review. June. . 1992. "The Dirty, Nasty Gym and Bathrooms." The DDU Review. February.

H., Jason. 1989. "Somebody Dieded." The DDU Review. November.

Higgins, Will. 2015. "The Unusual, Unforgettable Way Indy Buried Ryan White.” IndyStar.com. April 9. Accessed 24 September 2019. https://www.indystar.com/story/life/2015/04/09/buried-ryanwhite/25424315/.

J., Charles. 1989a. "Charles J. is Mr. Cool." The DDU Review. June.

. 1989b. "I'll Go CRAZY Without My MOUNTAIN DEW!!!" The DDU Review. October. . 1989c. "It's Too Hot in This Building." The DDU Review. May 
J., Charles and John L. 1989. “Attendant's Appreciation.” The DDU Review. June.

J., Jimmy. 1990. "No Roller Skating.” The DDU Review. April 1990.

Kelly, B.D. 2016. "Searching for the Patient's Voice in the Irish Asylums." Medical Humanities 42:87-91.

Kröger, T. 2009. “Care Research and Disability Studies: Nothing in Common?” Critical Social Policy 29 (3): 398-420.

LeFrançois, B.A., R. J. Menzies, and G. Reaume, eds. 2013. Mad Matters: A Critical Reader in Canadian Mad Studies. Toronto: Canadian Scholars' Press.

Leftridge, B. 1988. "Rehab Rap." The DDU Review. December.

Lewis, B. 2009. "Madness Studies.” Literature and Medicine 28:152-171.

M., Tommy. 1988. "Choking." The DDU Review. December.

Majerus, B. 2016. "Making Sense of the 'Chemical Revolution': Patients' Voices on the Introduction of Neuroleptics in the 1950s." Medical History 60:54-66.

McDonel, E.C., L. Meyer, and R. Deliberty. 1996. "Implementing State-Level Mental Health Policy Reforms in Indiana: Closing a State-Operated Psychiatric Hospital and Passing Major Mental Health Reform Legislation." International Journal of Law and Psychiatry 19 (3/4): 239-264.

Morse, J.M. and P.A. Field. 1995. Qualitative Methods for Health Professionals. 2nd ed. Thousand Oaks : Sage. Murat, L. 2011. L'homme qui se prenait pour Napoléon. Pour une histoire politique de la folie. Paris: Gallimard.

N. Vincent. 1989. "Smoking Rules.” The DDU Review. October.

Porter, R. 1985. "The Patient's View: Doing Medical History from Below." Theory and Society 14:175-198.

Read, J. and J. Reynolds, editors. 1996. Speaking Our Minds: An Anthology of Personal Experiences of Mental Distress and its Consequences. Houndmills: Macmillan.

Reiss, B. 2004. "Letters from Asylumia: The Opal and the Cultural Work of the Lunatic Asylum, 1851-1860." American Literary History 16 (1): 1-28.

Ripa, Y. 1990. Women and Madness. The Incarceration of Women in Nineteenth-Century France. Cambridge: Polity Press.

S., Jeffrey. 1988. "Steps on the Ward." The DDU Review. October.

S., Kenneth. 1989. "Ward Officers on Ward 34." The DDU Review. November.

S., Linda. 1988a. "My Best Friend Pat Buford." The DDU Review. October.

S., Linda. 1988b. "My Communication Class." The DDU Review. September.

Shipp, E. R. 1992. "Tyson Found Guilty on 3 Counts as Indianapolis Rape Trial Ends." New York Times. February 11. Accessed 10 March 2020. https:/archive.nytimes.com/query.nytimes.com/gst/fullpage-9F0 CE0DB133DF932A25751C0A964958260.html

Strauss, A. and J. Corbin. 1998. Basics of Qualitative Research: Techniques and Procedures for Developing Grounded Theory. 2nd ed. Thousand Oaks: Sage.

Whyde, K. 1988. "Capturing Pride in Print.” The Indianapolis Star. April 9: 37. Accessed on 12 March 2020. https://www.newspapers.com/clip/4861344/capturing-pride-in-print-indianapolis/.

Wilson, S. 2010. Voices from the Asylum: Four French Women Writers, 1850-1920. Oxford: Oxford University Press.

Publisher's Note Springer Nature remains neutral with regard to jurisdictional claims in published maps and institutional affiliations. 